\title{
Study on the status of logistics management in minor enterprises
}

\author{
Liyan Zuo ${ }^{1, a}$ \\ ${ }^{1}$ Department of industry and business administration, Daqing Vocational College, Daqing 163000 \\ China \\ azuoliyan82@126.com
}

Keywords: Logistics management; Minor enterprise; Logistics management system; Status

\begin{abstract}
With the rapid growth of the economy in China, minor enterprises have become an important part of the China's economy. However, as the world economy competition is becoming more and more intense, the pressure and challenges of the minor enterprises are increasing. Based on the analysis on the status and future prospects of logistics management in enterprises. In this paper, the status of logistics management in minor enterprises was discussed. The suitable logistics management system and internal management system were also explained in detail.
\end{abstract}

\section{Introduction}

The quality of logistics management is not only determines the management level of production and business activities, but also is the key to affect the competitiveness of enterprises. At present, many companies have begun to attach importance to logistics management, however, due to limited awareness of the logistics management, the actual work is still facing many problems [1-3]. Especially, the problem of some small and medium enterprises in this regard is particularly prominent, mainly for the following aspects:

First, the concept behind. People think the logistics management is only the transportation freight management or warehouse management, emphasis on the physical management and ignore the information systems management.

Second, methods and management tools behind. Especially, the management in minor enterprises is still manual, unable to adapt to rapid changes in modern society. In the enterprise logistics management, many enterprises still remain in the era of pen and paper, although some companies are equipped with computers, but no system or network, while it is also a lack of MRP, PC, artificial intelligence/expert systems, communications, bar code scanning and other advanced information technologies and applications in the logistics operation.

Third, the lack of professionals. Modern management must rely on modern knowledge of talent, competitiveness of enterprises in the final analysis is the competition of talent and knowledge competition [4]. Due to the deviation in terms of understanding the concept, logistics managers of minor enterprises also serious aging. Therefore, to solve the problems in logistics management, we must solve the problem of the concept of enterprise management, to figure out the content of logistics management, the only way to use the appropriate management methods and means in order to provide an appropriate staff, then to achieve logistics management purpose and play its due effect.

\section{Advanced logistics management concepts}

First, the concept of logistics management. Logistics refers to the original flow of all matter, it is an essential part of business activity. Currently, logistics management is a management process, the scope of logistics management throughout the supply of raw materials to the finished product provides, it is a systematic management process, through the coordination of material and information flow between customers, businesses and suppliers, so that the needs of the market are met. Therefore, we say that logistics management is a holistic concept.

${ }^{1}$ Corresponding author: Liyan Zuo (1973-), female, Acheng County, Heilongjiang Province, E-mail: zuoliyan82@126.com 
Second, connotation of logistics management costs. Any business activities of enterprises has a cost, the cost of logistics management mainly consists of the following aspects:

(1) Scale costs of material procurement: When you have selected materials and suppliers, material costs are relatively fixed period of time, but the size and purchasing bulk have a certain relationship. Therefore, how to determine the purchasing bulk is a key factor in controlling the cost of materials. The scale of procurement costs do not include the cost of materials, but the scale of procurement batch size affects the level of material procurement costs, up to a certain purchasing size to give preferential price, which we call the discounted prices, The cost difference due to the size called the purchasing size costs of the materials, in fact, it is the costs savings through bulk ordering.

(2) Holding costs: Inventory holding cost has some conceptual distinctions blur and difficult to determine, so, many companies just order the current bank rate multiplied by the inventory value plus some other costs as the inventory holding costs. In fact, inventory holding costs includes the cost of funds used inventory, inventory service costs, inventory costs and price risk losses.

(3) Warehousing costs: Most warehousing costs do not change with the change of inventory levels, but with the change of the number of storage locations. Storage cost includes the warehouse rent, warehouse depreciation, depreciation of equipment, handling costs, freight and packaging material costs and management fees.

(4) Opportunity cost: Opportunity cost is the loss of sales profits caused by those can not meet customer orders or demand.

(5) Logistics management costs: Management costs include logistics management and operations personnel related administrative costs and office software expenses.

(6) Transportation cost: Transportation cost refers to the cost by all transport activity of raw materials products by the enterprises, including direct transportation costs and management costs. To reduce the total cost of logistics, we need to strictly control expenditure in transport, to strengthen transport economic accounting. General enterprise merely take transport costs as logistics costs, in fact, it is not complete.

Third, composition analysis of logistics management cost. As the enterprise existing accounting system is based on labor and product to share the cost of doing business, so, the enterprise 's "income statement" has no direct record of logistics costs, therefore, to know the logistics cost of enterprises is relatively difficult. At this stage, the logistics cost is still a very vague area in logistics industry. An enterprise logistics cost calculation conceptual formula generally agreed by academics as follows:

Enterprise logistics management costs $=$ Transportation costs + holding costs + warehousing costs + logistics management costs

Obviously, it is classify and consideration by the basic functional activities of logistics management, I believe that total logistics costs should also take the material purchasing scale costs into account, that is the difference purchasing costs, and opportunity costs, and above all the individual costs of comprehensive. However, due to the cross-border and open character of logistics management and operation, it makes total logistics costs by a series of interrelated logistics activities both in different functional departments within the enterprise, and they are located in different partner companies outside. So, even with such a seemingly simple conceptual formula, it has still a lot of difficulty to accurately grasp the total cost of enterprise logistics.

The purpose of logistics management is to co-ordinate arrangements for the orderly, unified management information, to ensure the production activities normal and orderly manner to meet customer demand, while allowing total logistics costs can be controlled within the range. Of course, a lower cost is a goal, it is the process which need to be constantly improved, in this process, as long as the cost is in the budget or in the controllable range, the goal is achieved. Some enterprises pursuing so-called minimum is a misunderstanding. 


\section{Suggestion of logistics management reform in minor enterprises}

First, establish logistics management information system suitable for enterprises. From production planning, purchasing to warehouse management, logistics management jobs today and inventory control operations are very diverse, complex, how to make the total logistics costs in enterprises the most reasonable, to rely on artificial memory processing has been very difficult or impossible. If you can not guarantee the right purchase, inspection, quality assurance and delivery, it will lead to a waste of time, generate inventory, delay in delivery, increased costs, resulting in lost opportunities for customer service. Thus, it is essential to use the means of information such as the application information system. To use what kind of system, companies should depart from their own situation, find a system to meet their needs. I propose to start from the warehouse management system, since the data of warehouse is one of the most original source of logistics management, the warehouse is also the data exchange point between enterprises, suppliers and customers, it needs information management most, and warehouse system is also the easiest module to operate, thus, storage information management most likely to be adopted and brought enterprise benefits. Only the out of storage systems, the reporting system, inventories system of the warehouse is correct, complete, on this basis, then linked to procurement plans, production planning, financial systems, etc., in order to form their own logistics management information system.

Second, standardize their internal management procedures and systems. With the logistics information systems and other hardware means, if there is no internal management software and procedures, the data obtained is not true, and it can not be used in actual. This requires that enterprises must have their own standard operating procedures, that SOP-standard operating procedures, It refers to enterprise itself that they need operating specifications for each job. The development of SOP must be consistent with the actual situation of their own enterprise, to fully listen to the views of relevant departments and front-line staff, to get the consent of all personnel, once implemented it must be strictly, non-compliant behavior is not allowed, whether it is for anyone.

The minor enterprise managers tend to think their own enterprise is small, not complicated, does not require the development of operational procedures, which often result in practices changing, no tricks, over time, the final result can not control the situation. Therefore, regardless of their size, the work must have systems and processes, not only is the need for normal operation of enterprises, as well as management information required.

Third, establish mechanisms of training logistics management personnel. Since the personalized development of market consumer demand, quality of products and services for minor enterprises rely increasingly on competitive pricing and distribution system to solve the contradiction between supply and demand of time and space order meet consumer needs. Without modern logistics there is no real good product quality and service quality, enterprises need to further improve service and quality, which must have a high-quality logistics practitioners to achieve.

\section{Conclusion}

Currently, logistics management is a management process, the scope of logistics management throughout the supply of raw materials to the finished product provides, it is a systematic management process, through the coordination of material and information flow between customers, businesses and suppliers, so that the needs of the market are met. With the logistics information systems and other hardware means, if there is no internal management software and procedures, the data obtained is not true, and it can not be used in actual. This requires that enterprises must have their own standard operating procedures, that SOP-standard operating procedures. The minor enterprise managers tend to think their own enterprise is small, not complicated, does not require the development of operational procedures, which often result in practices changing, no tricks, over time, the final result can not control the situation. Therefore, regardless of their size, the work must have systems and processes, not only is the need for normal operation of enterprises, as well as 
management information required.

\section{References}

[1] Q. Zheng. Logistics management and the method of realizing modernization [J]. China Cement, 2002, vol.7, pp. 45-49.

[2] Y. Tao. Current situation and thinking of SMEs in logistics management [J]. Enterprise economy, 2011, vol. 1, pp. 58-60.

[3] X.L. Wang, H.J. Li. Research on the logistics cost and control [J]. Logistics Technology, 2006, vol. 3, pp. 21-25.

[4] H.T. Li. Longitudinal control of the logistics cost [J]. Business Management, 2015, vol. 5, pp.13-17. 